\title{
OS DEPUTADOS E 0 RIO: OS DEBATES DE 1853 SOBRE A NAVEGAÇÃO A VAPOR NO RIO AMAZONAS E 0 SISTEMA REPRESENTATIVO NO BRASIL MONÁRQUICO*
}

Vitor Marcos Gregório

Doutorando pelo Departamento de História da FFLCH-USP.

\section{Resumo}

Inseridos no contexto mais amplo da formulação de regras gerais para a navegação a vapor em rios internacionais, os debates acerca da navegação do rio Amazonas, ocorridos em 1853, demonstram a preocupação dos representantes do regime imperial em responder, da melhor forma possível, às pressões de potências estrangeiras pela abertura do grande rio. Isto sem nunca esquecer a realidade e as necessidades do Brasil, em meados do século XIX.

\section{Pallavras-chave}

Brasil Império • rio Amazonas • navegação a vapor.

\section{Abstract}

Participating in the formulation of general laws for steam navigation in international rivers, the discussions about the navigation of Amazon river, occurred in 1853, demonstrate the concern of the imperial political to respond to pressures from foreign countries by the opening of the great river, without forgetting context and the needs of Brazil, in mid-nineteenth century.

\section{Keywords}

Imperial Brazil • Amazon river • steam navigation.

\footnotetext{
${ }^{*}$ Pesquisa realizada com financiamento da Fapesp.
} 
No âmbito do processo de formação e consolidação do Estado nacional brasileiro, a questão da navegação do rio Amazonas possui uma importância fundamental. Isto decorre do fato de agregar uma série de problemas, como a definição territorial do Império, a relação deste com outros Estados - não só vizinhos, mas também potências mais distantes - o desenvolvimento e incorporação da região amazônica ao conjunto do país, entre outros. Estes fatores, agregados, tinham tal importância que a questão acabou adquirindo posição destacada nas discussões acerca dos projetos nacionais a serem implantados no país. Os debates e o papel do Parlamento no processo decisório acerca do tema são os objetos deste texto, que constitui parte de uma pesquisa maior, apresentada na forma de dissertação de mestrado. ${ }^{1}$

Antes, contudo, de passar à análise dos debates ocorridos no âmbito do Poder Legislativo imperial, é preciso destacar que a discussão em torno do tema da liberdade de navegação fluvial não era uma exclusividade brasileira. Estava inserida em um contexto mais amplo de formulação de princípios concernentes ao direito internacional, ocorrido em diversos países. Desta forma, os parlamentares do Império precisavam ter um aprofundado conhecimento desses processos decisórios, para adequar seus resultados, da melhor forma possível, à realidade e às necessidades do país.

Durante a época colonial ficava exclusivamente a cargo do país detentor das margens dos rios decidir sobre sua navegação. Neste sentido, uma vez garantida a Portugal a posse sobre as duas margens do rio Amazonas através do Tratado de Madri, assinado com a Espanha em 1750, ficou facultado àquele Império o direito de manter fechada a sua navegação valendo-se das prerrogativas garantidas pelo sistema colonial. Durante este período, portanto, as discussões sobre o Amazonas não se davam sobre o direito de navegar ou não suas águas, mas sim sobre a posse do seu curso, disputado por Espanha e Portugal e cedido ao último em uma mesa de negociações sem que, entretanto, coubesse a este país a posse de sua nascente, localizada na rica colônia do Peru.

Segundo Saboia de Medeiros, os princípios que regulavam a navegação de rios internacionais começaram a mudar em 1792, durante a Revolução Francesa. Neste momento, passou a ser aceita a ideia segundo a qual todos os

1 GREGÓRIO, Vitor Marcos. Uma face de Jano: a navegação do rio Amazonas e a formação do Estado brasileiro (1838-1867). Dissertação de Mestrado, História, FFLCH - USP, 2008. Disponível em versão digital no site www.teses.usp.br. 
ribeirinhos teriam direito a navegar nas águas dos rios comuns a eles. Neste sentido, quando em 1798 os mesmos franceses propuseram a livre navegação de alguns rios europeus durante o Congresso de Rastadt, não lograram alcançar qualquer êxito em sua proposta.

A liberdade de navegação de rios internacionais só passou a ser seriamente cogitada no Congresso de Viena de 1815, quando, graças a uma proposta francesa, o rio Reno foi aberto à navegação de todos os países. Foi o primeiro caso em que esta medida foi tomada, tendo servido de argumento, durante algum tempo, àqueles que defendiam que a abertura do rio Amazonas fosse decretada tendo-se por base este exemplo. Segundo o documento assinado pelas potências europeias, a liberdade de navegação seria admitida apenas sob a condição de que fosse aproveitada por navios mercantes, ficando estipulado que as taxas de trânsito, devidas pelos barcos que navegassem no rio, não poderiam ser aumentadas sem o concurso de todos os países ribeirinhos. Desta forma, buscava-se evitar que a criação de altos impostos servisse de obstáculo ao direito de livre navegação.

Outra medida de teor semelhante só seria adotada em 1839, quando o Tratado de Londres instituiu a liberdade de navegação no rio Escalda, sem que os Países Baixos, contudo, abrissem mão do direito de cobrar as taxas que julgassem necessárias dos barcos que navegassem no trecho do rio pertencente ao seu território. Em 1856, pelo Tratado de Paris, assinado logo após o auge das pressões internacionais pela abertura do Amazonas, adotou-se a liberdade de navegação para o chamado trecho marítimo do rio Danúbio, sem qualquer distinção de direitos entre os países ribeirinhos e os não ribeirinhos. Segundo este tratado, seria criada uma comissão europeia encarregada de cuidar das obras tendentes a melhorar a navegação do rio e de regular a forma pela qual se daria esta navegação. A jurisdição desta comissão foi ampliada para outros trechos do Danúbio em tratados internacionais assinados em 1865, 1878 e 1883, tornando predominante o princípio segundo o qual a livre navegação do rio deveria ser gerida por todos os países europeus, com iguais direitos, e organizados em uma comissão que, se não era permanente, deveria ao menos durar por muito tempo. ${ }^{2}$

Ainda que o princípio da liberdade de navegação nos rios internacionais estivesse ganhando cada vez mais força na primeira metade do século XIX,

2 Sobre a evolução da questão no direito internacional: MEDEIROS, Fernando Sabóia de. A liberdade de navegação do Amazonas (relações entre o Império e os Estados Unidos da América). Rio de Janeiro: Companhia Editora Nacional, 1938, p. 13-20. 
quando os debates sobre a questão se desenrolaram no Brasil, ainda estava longe de se tornar dominante no direito internacional. Até 1856, apenas os rios Reno e Escalda estavam abertos a todos os países, fato que seria citado nos debates parlamentares como uma razão poderosa para manter a navegação do rio Amazonas restrita apenas aos ribeirinhos. Afinal, se nem as maiores potências do mundo haviam ainda adotado completamente este princípio, por que o Império deveria fazê-lo? Para responder às pressões internacionais pela abertura da navegação do grande rio, decidiu-se que o melhor seria realizar esta atividade com capitais nacionais e auxílio do governo imperial. Em 1852, o Poder Executivo adotou esta medida, assinando com o futuro barão de Mauá um contrato baseado em termos que agradavam ambas as partes. Mas não ao Poder Legislativo. O desenrolar das discussões acerca deste documento levanta muitas questões que auxiliam no entendimento do funcionamento do sistema político imperial em meados do século XIX.

\section{Os debates de 1853}

O ano de 1853 marcou um recrudescimento das discussões acerca da navegação a vapor do rio Amazonas na Câmara dos Deputados, motivadas pelo Decreto $n^{\circ} 1.037$, de 30 de agosto de 1852. Por este documento, o governo imperial concedia a Irineu Evangelista de Souza o direito de fundar uma companhia para realizar a dita navegação, mediante uma série de privilégios e condições. Neste sentido, previa a concessão, por parte do governo imperial, de uma subvenção pecuniária acrescida de um privilégio de exclusividade que deveria vigorar pelos próximos trinta anos. Além disso, previa também a cessão das terras necessárias para a fundação de sessenta colônias nas margens do rio, a serem habitadas por índios ou imigrantes estrangeiros, além de um terreno no qual deveria ser construído um dique na cidade de Belém. Em contrapartida, a companhia ficava obrigada a manter linhas de vapores regulares no rio Amazonas, a nunca operar com um capital inferior a mil e duzentos contos de réis e a fundar e manter as sessenta colônias nas margens deste rio, tão logo fosse obtida a aprovação do Poder Legislativo. ${ }^{3}$

\footnotetext{
3 Anais da Câmara dos Deputados. Sessão de 11 de julho de 1853, p. 152-153. Todos os debates presentes nos Anais da Câmara dos Deputados citados neste texto estão disponíveis, em versão eletrônica, no site www.camara.gov.br.
} 
Formulado nesses termos, o decreto foi submetido à Câmara dos Deputados em 1853. Como parte do processo de apreciação do objeto, foi primeiramente enviado para análise da comissão de comércio, indústria e artes, formada pelos deputados Viriato Bandeira Duarte (Mato Grosso), Augusto Frederico de Oliveira (Pernambuco) e Frederico de Almeida e Albuquerque (Paraíba), de quem se esperava a formulação de um parecer sobre as decisões tomadas pelo governo. No voto emitido por esta comissão, em 9 de julho de 1853, e apresentado à Câmara dois dias depois, aprovava-se a concessão das terras feita pelo governo, tanto para a fundação das colônias como para a construção do dique em Belém. Ficava permitido, ainda, que a companhia alienasse e contratasse os ditos terrenos com empresas de colonização, famílias ou indivíduos para transferência de colonos, e nacionalizasse os seus vapores independentemente da sua origem - sendo a sua aquisição isenta dos direitos relativos à transferência de propriedade ou matrícula, e sua tripulação tratada com os mesmos direitos devidos às de embarcações nacionais. No documento não havia nenhuma palavra acerca da concessão da subvenção pecuniária, nem do privilégio de exclusividade por trinta anos. ${ }^{4}$

Nos debates parlamentares que se seguiram à apresentação deste voto, várias questões auxiliam no entendimento da organização do Estado imperial brasileiro e dos projetos que cercavam a problemática do melhoramento da inserção da região norte do país no conjunto político e econômico da nação. Neste sentido, foram surgindo, discurso após discurso, desde argumentações relacionadas à conveniência do estabelecimento da navegação a vapor no rio Amazonas - unanimemente defendida pelos representantes de diferentes províncias - até falas emocionadas acerca da difícil e por vezes incerta relação entre os poderes Executivo e Legislativo. Por fim, a discussão acabou polarizando-se entre defesas e ataques ao privilégio de exclusividade concedido a Irineu Evangelista de Souza. Ao mesmo tempo em que estes deputados estavam discutindo uma questão concreta, estavam também pensando nos termos mais amplos de um projeto nacional, ao passo que buscavam defender suas prerrogativas estabelecidas seguindo a lógica de um sistema representativo. A equação entre estes elementos levou a uma situação de grande tensão entre os grupos de parlamentares, que só se resolveu com a decisão pela reforma do contrato originalmente firmado entre o governo e o futuro barão de Mauá. O Poder Executivo teve, então, de

\footnotetext{
4 Idem.
} 
recuar de uma decisão anteriormente tomada diante das discussões e pressões do Poder Legislativo, especificamente da Câmara dos Deputados.

\section{Projetos para o desenvolvimento da Amazônia: navegar para desenvolver}

A ocupação da Amazônia foi uma das preocupações nas discussões parlamentares acerca do projeto apresentado pelo governo imperial em 1853. A questão que mereceu maior cuidado por parte dos deputados foi o privilégio de exclusividade para a navegação a vapor do rio Amazonas, válida por um período de trinta anos, concedida à companhia fundada por Irineu Evangelista de Souza. O tema foi discutido sob duas óticas distintas: por um lado, foi debatida a sua conveniência econômica, no sentido de verificar se esta medida seria, de fato, a melhor forma de se promover o desenvolvimento da região amazônica. Por outro lado, sob um ponto de vista político, foi discutido se o governo imperial possuía jurisdição para conceder tal regalia à companhia, evidenciando a por vezes difícil relação entre os poderes Executivo e Legislativo imperiais.

Quanto à conveniência econômica da medida, posições discordantes rapidamente se apresentaram. O deputado pela província do Maranhão, Cândido Mendes de Almeida, foi uma das principais vozes a se levantar contra o privilégio. Ele reconheceu a importância da navegação do Amazonas, muitas vezes apresentada como crucial para o futuro do país e capaz de “enormes lucros” para a nação e para quem empreendesse tal atividade, mas se mostrou absolutamente contrário à concessão do privilégio de exclusividade a uma única empresa. Principalmente quando se tratava de uma companhia com capital de mil e duzentos contos de réis - considerada muito pequena para tamanho empreendimento - e de uma vantagem válida pelo período de trinta anos - entendido como extremamente longo. Para o deputado, a melhor forma de favorecer a navegação na região amazônica seria oferecer uma subvenção grande o suficiente para que uma companhia iniciasse a atividade, mas mantendo garantida a possibilidade de concorrência.

Para justificar esta posição, Mendes de Almeida lançou mão de alguns argumentos. O primeiro deles é calcado na ideia de que uma subvenção financeira já seria suficiente para garantir um lucro certo para a companhia que se propusesse a realizar a navegação a vapor do rio Amazonas, não sendo necessário, portanto, que esta detivesse o monopólio como forma de garantir a sua viabilidade. Se a subvenção, em determinadas circunstâncias, passasse a não ser mais suficiente, poderia então ser aumentada de acordo com as novas necessidades. Contra uma possível resposta no sentido de que esta medida poderia ser onerosa demais 
para os cofres públicos, o deputado pelo Maranhão adiantava que o sacrifício seria recompensado amplamente pelos lucros que a navegação traria ao país, além do que sacrifícios ainda maiores já tinham sido realizados na região da bacia platina, sem maiores resultados práticos. Isto posto, por que então não se sacrificar também pelo rio Amazonas, que poderia dar um retorno mais positivo? Além do que, a exclusividade dada a uma companhia pequena para navegar tamanho rio pelo prazo de trinta anos traria um prejuízo para o país ainda maior do que o representado pelo dinheiro que seria gasto com a subvenção. ${ }^{5}$

Este argumento do deputado Mendes de Almeida remete para uma questão extremamente cara aos administradores imperiais. O problema da precariedade dos meios de comunicação não era exclusivo da região amazônica, em meados do século XIX. Datam da mesma época diversas reclamações e pedidos vindos de diversas localidades, necessitadas de estradas e linhas de navegação para facilitar seu comércio, e para fazer com que as autoridades provinciais se fizessem mais presentes nos rincões mais distantes de suas jurisdições territoriais. Estas reclamações adquiriam mais força quando, conjugadas a contingências de ordem interna, surgiam questões referentes às fronteiras externas do Império. Neste sentido, em um momento de recrudescimento das tensões na bacia do rio da Prata - após anos de conflitos contra os farroupilhas do Rio Grande do Sul - o governo central procurou, através de investimentos em rotas de comunicação e da criação de uma nova unidade administrativa, tornar mais efetiva sua presença na região. Se é verdade que medidas semelhantes foram tomadas para a Amazônia, a fala de Mendes de Almeida deixava transparecer que ainda assim os esforços para resolver o problema no sul do país foram mais avultados e, entretanto, com poucos resultados até o momento do discurso. A veracidade desta afirmação do representante do Maranhão é um dado que precisa ser verificado, mas é um bom indício de que, mesmo nas regiões comparativamente mais próximas da corte, a questão das linhas de comunicação era um elemento que estava na ordem do dia das preocupações do governo imperial.

O deputado Mendes de Almeida afirmou, ainda, que a concorrência seria extremamente benéfica para a região amazônica, pois apressaria o desenvolvimento do seu comércio tornando-a, em pouco tempo, autossuficiente. Em contrapartida, o decreto tal como estava formulado traria outro malefício além dos já citados, que seria o de deixar a navegação do Amazonas brasileiro em

\footnotetext{
Anais da Câmara dos Deputados. Sessão de 1 de agosto de 1853, p. 7-8.
} 
desvantagem se comparada à navegação realizada nos demais países ribeirinhos. Estes países - Peru, Nova Granada, Equador e Venezuela - teriam rejeitado firmar contrato com Irineu Evangelista de Souza e poderiam, portanto, gozar da liberdade de navegação no rio enquanto os brasileiros estariam presos a um contrato de exclusividade. As consequências de semelhante acontecimento seriam desastrosas para o Império:

O que acontecerá é que peruvianos (sic), os equatorianos, os habitantes da Nova Granada e Venezuela, todos navegarão livremente o Amazonas com proveito seu, e nós que possuímos o ponto mais importante desse rio, como é a sua embocadura, e em grande extensão e sua parte mais navegável, seremos reduzidos à navegação promovida por uma só companhia, e de tão pequenos fundos, que dirigirá a mesma navegação de conformidade com o seu interesse, com o monopólio que se lhe concede. ${ }^{6}$

Ao conceder um privilégio de exclusividade na navegação do rio a uma companhia considerada pequena demais para arcar com semelhante responsabilidade, o governo imperial estaria se colocando em situação de inferioridade com relação aos seus vizinhos, criando um verdadeiro funil que dificultaria o escoamento da produção andina para os mercados atlânticos, deixando com isso de ganhar com este lucrativo comércio.?

De fato, o ponto central do projeto do deputado maranhense para a região norte do Império passava pela necessidade de se promover a concorrência entre diversas companhias na navegação a vapor dos rios amazônicos, como condição para o seu desenvolvimento. Para Mendes de Almeida, apenas a concorrência poderia servir de garantidora da qualidade dos serviços a serem prestados, uma vez que o risco de perda de mercado para uma empresa concorrente acabaria obrigando todas as companhias a realizarem a navegação com os melhores barcos, com a maior pontualidade e com os melhores preços possíveis, seguindo uma lógica já consagrada no liberalismo econômico clássico. Ao contrário, o projeto, como estava sendo apresentado acabaria causando uma acomodação na companhia do futuro barão de Mauá, uma vez que, detendo um privilégio de monopólio da navegação do rio Amazonas válido por trinta anos, esta teria como lógica principal a busca da consecução apenas de seus interesses mais imediatos, deixando os objetivos e necessidades da nação em segundo plano.

\footnotetext{
6 Idem, p. 8.

Idem, p. 7-10.
} 
Assim, acabaria por privilegiar apenas o aumento de seus lucros, em prejuízo da qualidade da navegação da região amazônica e, consequentemente, do desenvolvimento de todo o norte do Império.

Uma grande novidade da proposta do deputado maranhense foi a defesa da contratação de companhias mistas - nacionais e estrangeiras - para contornar este problema e realizar vantajosamente a navegação a vapor do rio Amazonas. Proposta que, sintomaticamente, nem foi seriamente cogitada pelos demais deputados. Para Mendes de Almeida, seria "sobejamente conhecido” que no Império não havia capital disponível para realizar tamanho empreendimento. Se os próprios brasileiros não se arriscavam a realizar a navegação sem excessivas cautelas, que se atraísse então o capital estrangeiro para realizá-la, sob inspeção do governo. Se esta prática já era adotada largamente na construção de estradas de ferro, não havia razão, ponderava o deputado, para que não se fizesse o mesmo com a navegação de um grande rio como o Amazonas, atividade mais fácil e que prometia muito melhor futuro. Assim, a navegação da bacia amazônica não estaria sendo realizada há muito tempo porque se teimava em confiar tal empresa a companhias brasileiras, menores em capital e mais necessitadas de privilégios do que as companhias mistas ou estrangeiras. ${ }^{8}$

Esta passagem da discussão do dia 18 de agosto de 1853 é instigante dada a fundamentação dos argumentos, que traz um projeto alternativo para a navegação a vapor do rio Amazonas, e o tratamento que este recebeu quando de sua formulação e mesmo posteriormente. No ato do discurso, surgiu prontamente a oposição de outros parlamentares, como, por exemplo, o aparte do deputado por Minas Gerais, Francisco de Paula Cândido, que dizia: “com capitais estrangeiros, não vou por aí”. ${ }^{9}$ Além disso, o assunto não foi mais retomado seriamente em nenhum discurso posterior - apenas o outro deputado pelo Maranhão, Lisboa Serra, faria breve referência a ele novamente -, o que demonstra a quase completa rejeição da casa com relação a esta ideia, que precisaria ainda de mais onze anos para voltar a ser considerada, agora com maciço apoio de todos os deputados. Era já o momento decisivo para a aprovação da abertura da navegação do rio Amazonas a todas as bandeiras estrangeiras, determinada por decreto de dezembro de 1866.

Em 1853, entretanto, a conjuntura era diferente, o que motivou os deputados a não apoiar semelhante projeto. Principalmente no âmbito externo, o

8 Anais da Câmara dos Deputados. Sessão de 18 de agosto de 1853, p. 238-241.

9 Idem, p. 239. 
Império tinha que conviver com questões de difícil solução, como as relações cada vez mais tensas com os países platinos, ao sul, e as disputas fronteiriças com Inglaterra e França, ao norte. Ainda no tocante à região amazônica, outra ameaça se tornava cada vez mais preocupante aos administradores imperiais. Os Estados Unidos, potência mundial em ascensão, demonstravam interesse cada vez maior em estabelecer presença na região. Neste sentido, campanhas intensas destinadas a insuflar a opinião pública daquele país - como a empreendida na imprensa pelo tenente da marinha Matthew Fontaine Maury, nesta mesma época - acusavam o governo brasileiro de contrariar os interesses da humanidade ao manter a região fechada a outros países, deixando-a entregue a seus "parcos recursos", insuficientes para desenvolvê-la. Criava-se assim, na ótica desses políticos, um arcabouço teórico semelhante ao que, em outras situações, já havia permitido àquele país anexar o Texas e metade do território mexicano através de guerras. Dessa forma, atrair capitais estrangeiros para as margens do Amazonas poderia colocar em risco a soberania brasileira sobre esta região, seja devido à ameaça de perda de território para Inglaterra e França, seja por conta da campanha estadunidense que provocava, já em meados do século XIX, temores relativos ao caráter expansionista de suas políticas externas. ${ }^{10}$

O deputado pela província da Bahia, Ângelo Muniz da Silva Ferraz, também defendeu um projeto de desenvolvimento e inserção da região amazônica no conjunto do Império bastante parecido com o apresentado por Mendes de Almeida. Já em sua primeira intervenção nesta discussão, em 11 de agosto de 1853, o deputado propôs o adiamento da mesma até que o ministro do Império, Francisco Gonçalves Martins, pudesse comparecer ao plenário para prestar alguns esclarecimentos sobre o decreto que estava sendo discutido, como, por exemplo, o alcance do privilégio de exclusividade:

\footnotetext{
${ }^{10}$ Sobre o tema, ver MEDEIROS, Fernando Sabóia de, op. cit.; LUZ, Nícia Vilela. AAmazônia para os negros americanos. Rio de Janeiro: Saga, 1968; SAMPAIO, Maria Clara Sales Carneiro. Fronteiras negras ao sul: A proposta dos Estados Unidos de colonizar a Amazônia brasileira com afrodescendentes norte-americanos na década de 1860. Dissertação de Mestrado, História, FFLCHUSP, 2008. Disponível em versão digital no site www.teses.usp.br; e MEDEIROS, Vera Alarcón B. Incompreensível colosso - a Amazônia no início do Segundo Reinado (1840-1850). Tese de Doutorado, História, Faculdade de Geografia e História da Universidade de Barcelona, 2006.
} 
Estou pronto para dar à navegação direta até a nossa extrema, ou até Nauta [no Peru], conforme os tratados existentes, esse privilégio; mas acho que a navegação intermédia deve ficar livre. ${ }^{11}$

Como se viu no desenvolvimento posterior das discussões, o deputado Ferraz não estava assim tão disposto a aceitar semelhante privilégio. De fato, na agitada sessão do dia 18 de agosto de 1853, na presença do ministro, o deputado baiano, que havia feito o requerimento pelo adiamento da discussão, foi o primeiro a tomar a tribuna. Em sua fala, retomou argumentos já defendidos por Mendes de Almeida, como as ideias segundo as quais o melhor para a região amazônica seria cancelar o privilégio de exclusividade substituindo-o por um subsídio financeiro, uma vez que a companhia criada para a navegação do rio Amazonas possuía um capital pequeno demais para a realização de semelhante atividade. ${ }^{12}$

Ainda que não tenha alcançado a completa adoção do seu projeto para a região norte, Ângelo Muniz da Silva Ferraz foi o responsável por uma emenda aprovada juntamente ao decreto, e que alteraria profundamente o seu sentido. Por esta emenda, apresentada à Câmara imediatamente antes da discussão e votação realizadas no dia 19 de agosto de 1853, o contrato realizado entre o governo imperial e a companhia de Irineu Evangelista de Souza ficaria aprovado, mas o privilégio de exclusividade da navegação pelo período de trinta anos deveria ser resgatado pelo governo mediante indenização, do modo que julgasse mais conveniente. ${ }^{13}$ Desta forma, ficava garantido que parte dos projetos de Mendes de Almeida e Ângelo Muniz da Silva Ferraz, entre outros deputados, seria posta em prática, frustrando, também em parte, o projeto que o governo imperial e seus defensores no parlamento haviam concebido para a região amazônica.

No entanto, nem tudo foram críticas ao contrato celebrado entre o governo imperial e o futuro barão de Mauá. Nas discussões ocorridas na Câmara dos Deputados, Viriato Bandeira Duarte, deputado pela província do Mato Grosso e membro da comissão de comércio, indústria e artes, tomou para si a tarefa de defender o documento e o voto favorável a ele. Já no primeiro dia de discussões, o representante mato-grossense fez alguns apartes à fala de Mendes de Almeida para afirmar, primeiramente, que sem o privilégio de exclusividade não haveria condições de navegar o Amazonas. Defendeu ainda que os lucros e vantagens

\footnotetext{
${ }^{11}$ Anais da Câmara dos Deputados. Sessão de 11 de agosto de 1853, p. 168.

${ }^{12}$ Anais da Câmara dos Deputados. Sessão de 18 de agosto de 1853, p. 236.

${ }^{13}$ Anais da Câmara dos Deputados. Sessão de 19 de agosto de 1853, p. 253.
} 
desta empresa, apontados por Mendes de Almeida, viriam apenas “lá no futuro”, e que, embora este deputado afirmasse que várias empresas se interessariam por navegar o rio Amazonas, “o grande caso é que nenhuma apareceu antes dessa companhia [de Irineu Evangelista de Souza]”. ${ }^{14}$ Assim, foram introduzidas, com estes apartes, algumas ideias que nortearam a defesa do decreto, ao menos no que se referia à questão da exclusividade.

No dia 2 de agosto de 1853, segundo dia de discursos acerca da matéria, Viriato Bandeira Duarte teve a oportunidade de tomar o lugar na tribuna. Sua fala teria dois objetivos principais: primeiramente expor as principais razões pelas quais a comissão aprovou a resolução que estava em discussão, apresentando questões acerca da relação entre os poderes Executivo e Legislativo do Império, que serão analisadas adiante. E em segundo lugar, refutar as argumentações que Cândido Mendes de Almeida formulou contra esta mesma resolução. Ao refutar as argumentações do deputado maranhense e defender o contrato firmado entre o governo imperial e Irineu Evangelista de Souza, Viriato Bandeira Duarte expôs com bastante clareza qual era seu projeto para o rio Amazonas e toda a região norte do país. Assim, o deputado afirmou que o exclusivismo na navegação do rio Amazonas não só era um bem, como se mostrava congruente com a política do governo, que sempre havia dado algum tempo de exclusividade para as empresas que se prestassem à navegação no Brasil. Assim sendo, haveria dois motivos principais pelos quais a comissão acertara ao aprovar o projeto que lhe havia sido apresentado. O primeiro deles era o fato de que a criação de colônias-modelo nas margens do rio Amazonas, e, portanto, nas proximidades das tribos indígenas habitantes da região, seria o meio mais fácil e certo de civilizá-los. O contraponto nesta questão eram os Estados Unidos, um exemplo a ser evitado. Aqui não deveria ser buscado o afastamento dos indígenas como acontecia lá, mas sim a sua incorporação e civilização, em uma tarefa que faria com que o Império atingisse resultados mais positivos e desejáveis do que os alcançados na "América inglesa". ${ }^{15}$

O segundo motivo era bem mais prosaico: o governo já havia acertado tais concessões com Irineu Evangelista de Souza, que, por sua vez, já havia montado uma companhia para navegar o rio Amazonas contando com estes privilégios. Neste estado de coisas, não caberia ao Parlamento "acabar com a inviolabilidade dos contratos”, princípio reputado sagrado, levando assim o governo a

\footnotetext{
${ }^{14}$ Anais da Câmara dos Deputados. Sessão de 1 de agosto de 1853, p. 9.

${ }^{15}$ Anais da Câmara dos Deputados. Sessão de 2 de agosto de 1853, p. 27-28.
} 
cair em descrédito. Viriato acabou admitindo que a ausência destes privilégios não traria consequências para a companhia, uma vez que ninguém se animaria a competir com ela nesta atividade pela sua falta de atrativos imediatos. Mas, se o contrato já estava firmado e em execução, seria um retrocesso decidir pela reformulação de seus pontos principais. ${ }^{16}$

Da mesma forma, o deputado pela província de Mato Grosso concordou com Mendes de Almeida no sentido de ser, em tese, contra a concessão dos privilégios de exclusividade, mas alegou:

Quando um país é novo e começa na vida da civilização, esse país tem necessidade, para que apareça a navegação em seus rios e em suas costas, de oferecer garantias e privilégios exclusivos, porque de outra forma não pode animar a criação de vias de comunicação e gozar dos progressos que aspira a estabelecer em seu seio.

Quando, porém, o país tem chegado à época em que já essa animação para criação de vias de comunicação por mar e terra é dispensável, oferecendo elas por si mesmas interesses a companhias ou a particulares que se dedicarem a tais empresas, então é um mal a concessão de privilégios exclusivos. Mas nós ainda estamos muito longe dessa época, e tratando da especialidade, a navegação a vapor do rio Amazonas, direi que ainda agora principiamos. ${ }^{17}$

O deputado argumentava, para reforçar sua posição, com os exemplos dos Estados Unidos e da Inglaterra, onde, no início da abertura de suas vias de navegação, também foi preciso conceder privilégios de exclusividade. ${ }^{18}$

Essencialmente, o discurso de Viriato Bandeira Duarte estava calcado em uma ideia precisa acerca da navegação do rio Amazonas. Ela era uma empresa fundamental para o desenvolvimento do país, na medida em que tornaria possível a incorporação de uma grande quantidade de mão-de-obra indígena, até então inaproveitável devido a seu estado selvagem. Mais do que isto, esta incorporação se daria graças à fundação de colônias-modelo na proximidade das tribos, o que também levaria população civilizada para trabalhar nas margens dos rios, além de garantir a ocupação de regiões ainda contestadas por nações estrangeiras. Este processo de defesa formulado pelo Estado imperial acabaria sobrevivendo à proclamação da República e adentraria o século XX. Ao mesmo

\footnotetext{
${ }^{16}$ Idem, p. 28.

${ }^{17}$ Idem.

${ }^{18}$ Idem, p. 28-29.
} 
tempo, faria aparecer a navegação em toda aquela região, levando o comércio e, portanto, mais desenvolvimento ao norte do Império.

Neste sentido, a concessão do privilégio de exclusividade previsto pelo decreto governamental era um mal necessário. Afinal, pelo que se conhecia no momento acerca do rio Amazonas, ele não prometia nem lucros nem riqueza no curto prazo, o que automaticamente desencorajava investimentos imediatos em sua navegação. De nada adiantaria tentar incentivar uma concorrência que jamais ocorreria na região, uma vez que não existiam, ainda, quaisquer interesses econômicos que atraíssem investimentos financeiros. Estes seriam os responsáveis pelo início de um ciclo econômico que acarretaria o desenvolvimento e a completa inserção da região norte ao conjunto político e econômico do Império. E para que esse ciclo benéfico pudesse ser iniciado, a intervenção do Estado, representada pela concessão do privilégio de exclusividade, se tornava indispensável.

Essas ideias foram compartilhadas pelo ministro do Império, Francisco Gonçalves Martins, nos relatórios que apresentou à Câmara dos Deputados, em 1853 e $1854,{ }^{19}$ e nas breves intervenções que fez na sessão de 18 de agosto de 1853. Nestes discursos, o ministro afirmou que as vantagens concedidas à companhia de Irineu Evangelista de Souza não eram tão grandes assim. Tratava-se, segundo ele, mais de uma empresa patriótica do que propriamente voltada para o lucro, dado o caráter da atividade a ser realizada - que levaria a uma situação de prejuízo, ao menos no início da empreitada. Além disso, o governo não havia conseguido realizar o contrato com o futuro barão de Mauá sem conceder-lhe o privilégio de exclusividade pelo período de trinta anos. E sua anulação, seguida do aumento da subvenção, acabaria levando indiretamente à manutenção da mesma concessão, já que nenhuma outra companhia teria condições de competir com alguém tão fortemente protegido pelo governo imperial. ${ }^{20}$

Uma questão retomada pelo ministro Francisco Gonçalves Martins em seu discurso, de especial relevância, é a da fundação de colônias nas margens do rio Amazonas. O contrato celebrado entre o governo imperial e o futuro barão de Mauá previa que a companhia por ele criada deveria fundar sessenta colônias de estrangeiros ou indígenas nas imediações do rio e de seus afluentes, devendo ser

\footnotetext{
${ }^{19}$ Relatório do Ministério do Império, 14 de maio de 1853, p. 37-40, e Relatório do Ministério do Império, 14 de maio de 1854, p. 21-23. Os relatórios de todos os ministérios do período imperial estão presentes, em versão digital, no site http://wwwcrl-jukebox.uchicago.edu/bsd/ bsd/hartness/minopen.html.

${ }^{20}$ Anais da Câmara dos Deputados. Sessão de 18 de agosto de 1853, p. 241-242.
} 
os estrangeiros da nacionalidade que fosse designada pelo governo. Para isso, receberia em doação as terras que julgasse indispensáveis para o empreendimento. ${ }^{21}$ Para Ângelo Muniz da Silva Ferraz, a fundação de colônias na região amazônica possuía, assim como para o ministro, importância acentuada, a ponto de o deputado baiano acrescentar entre suas críticas ao contrato o fato de não ter sido estabelecido um prazo máximo para que a companhia as realizasse..$^{22}$ Gonçalves Martins respondeu afirmando que a definição deste prazo não era necessária, uma vez que interesses econômicos acabariam impelindo a companhia a realizar essas fundações enquanto ainda estivesse recebendo os subsídios pecuniários previstos no contrato, ou seja, durante os primeiros quinze anos do privilégio. ${ }^{23}$

Contrariamente ao ministro do Império, Cândido Mendes de Almeida acreditava que a fundação dessas colônias não seria um ônus para a companhia, mas sim um outro privilégio, ainda que de resultados tardios. E exatamente por conta da demora nesses resultados poderia ser justificado o privilégio de exclusividade no tocante apenas a esta concessão:

$\mathrm{Eu}$, senhores, não me oponho ao privilégio dado à companhia quanto às colônias que fundarem...

Sr. ministro do Império: Não é privilégio, é um ônus.

Sr. Mendes de Almeida: Entendo que é um privilégio à companhia o dar-se-lhe o exclusivo de navegar e de comerciar com estas colônias; se fosse um ônus, ela o não quereria, rejeitá-lo-ia, ficaria satisfeita somente com o exclusivo da navegação a vapor. Ela vai fundar colônias com vistas de um comércio de alta importância no futuro.

Sr. Pereira da Silva: É um benefício para o país.

Sr. Mendes de Almeida: Não contesto, e aplaudo; mas não se pode negar que a companhia também espera auferir lucros, e lucros não fictícios, porém reais, com o seu estabelecimento; do contrário, não quereria encarregar-se do estabelecimento dessas colônias. No presente caso, como a companhia tem de empregar capitais muito avultados somente com a esperança de lucros em verdade demorados, o privilégio é bem entendido; mas para a navegação, continuo a pensar que não é conveniente o exclusivo. ${ }^{24}$

\footnotetext{
${ }^{21}$ Decreto no $^{1.037}$, de 30/8/1852. In: Coleção das Leis do Império do Brasil, tomo 15, parte 2a seção $75^{a}$. Site da Câmara dos Deputados - www.camara.gov.br., p. 362.

${ }^{22}$ Anais da Câmara dos Deputados. Sessão de 18 de agosto de 1853, p. 235.

${ }^{23}$ Idem, p. 237.

${ }^{24}$ Idem, p. 240.
} 
Assim, ainda que sob diferentes pontos de vista, a conveniência da fundação de colônias nas margens do rio Amazonas aparece como um dos poucos consensos nessa discussão, fato indicativo de um ponto de convergência nos diferentes projetos defendidos para a região. Este ponto encontra-se no reconhecimento de que o povoamento do norte do Império, bem como a assimilação dos indígenas aí localizados, configurava-se como um elemento fundamental para a garantia do seu desenvolvimento. Ainda que neste momento a obrigatoriedade de fundar colônias fosse consenso na Câmara, quatro anos depois esta cláusula acabaria sendo suprimida do contrato, devido à incapacidade da Companhia de Navegação e Comércio do Amazonas em cumprir esta determinação. A fundação de colônias na Amazônia acabaria sendo temporariamente descartada frente à necessidade mais urgente de estabelecer a navegação a vapor nos seus rios. Esta hierarquização de prioridades diz muito sobre as formas pelas quais se esperava alcançar um maior desenvolvimento para o norte do país e sobre as alterações sofridas pelas políticas adotados com esta finalidade. ${ }^{25}$

Além das posições opostas defendidas, respectivamente, por Cândido Mendes de Almeida e Ângelo Muniz da Silva Ferraz, de um lado, e por Viriato Bandeira Duarte e pelo ministro do Império - representante da postura oficial do governo imperial -, de outro, pode ser percebida a defesa de alguns projetos que incorporam princípios de ambos os grupos. Este foi o caso das posições adotadas por dois representantes da região amazônica; o deputado da recém-criada Província do Amazonas, João Wilkens de Mattos, e o deputado pela Província do Grão-Pará, Fausto Augusto de Aguiar. Ambos aproveitaram a discussão do dia 11 de agosto de 1853, acerca do pedido de adiamento das deliberações, para expor as principais ideias do projeto que defendiam para a região que representavam.

João Wilkens de Mattos não se mostrou tão convencido acerca da clareza do contrato celebrado entre o governo imperial e Irineu Evangelista de Souza. Embora tenha afirmado ser defensor da criação da companhia de navegação a vapor e do exercício de suas atividades na região amazônica, defendeu o adiamento da discussão até que o ministro do Império pudesse esclarecê-lo completamente. Afirmava ter uma interpretação do contrato e do projeto completamente diferente da apresentada pelo deputado Viriato Bandeira Duarte. Para Wilkens de Mattos, a letra do contrato deixava bem claro que o privilégio de exclusividade dado à companhia do futuro barão de Mauá restringia-se

$\overline{{ }^{25} \text { Sobre este assunto, }}$ ver GREGÓRIO, Vitor Marcos, op. cit. 
apenas a dois trechos bem delimitados - o compreendido entre Belém, capital do Pará, e Barra, capital do Amazonas; e entre esta cidade e Nauta, no Peru -, com obrigação de que os vapores tocassem nos portos intermediários a estas localidades. Assim sendo, sem que fosse plenamente esclarecida a inteligência do contrato, e, consequentemente, do projeto em discussão, acabariam sendo criados sérios problemas para o futuro, como, por exemplo, no momento em que outras companhias se propusessem a realizar navegações marginais às duas linhas de vapores. ${ }^{26}$ Ainda, poderia ocorrer a seguinte situação:

O governo poderá dizer à companhia: os vapores devem tocar em Monte Alegre, que está dentro de um rio, mas a companhia, que não tem essa obrigação, responderá dizendo: não é isso minha obrigação. A companhia portanto só tocará nos pontos que convencionar com o governo e lhe for conveniente. ${ }^{27}$

Outro fato contestado por Wilkens de Mattos foi a incorporação da expressão “companhia de navegação e comércio” ao nome da empresa de Irineu Evangelista de Souza. Segundo o deputado, a expressão poderia dar margem a que, no futuro, a companhia pudesse reivindicar para si também o monopólio do comércio nas regiões em que estivesse navegando, o que deveria ser evitado a todo custo. ${ }^{28}$

Em seguida, tomou a tribuna o deputado pela Província do Grão-Pará, Fausto Augusto de Aguiar, também em defesa do adiamento da discussão até que maiores esclarecimentos pudessem ser prestados. Seus argumentos e ideias foram bastante parecidos com os apresentados por João Wilkens de Mattos:

(...) é da maior utilidade que todas as partes desse contrato sejam explicadas e definidas, por modo que para o futuro não se possam suscitar novas dúvidas a seu respeito. ${ }^{29}$

O deputado pelo Grão-Pará também indagou sobre a presença da palavra comércio no nome da companhia a ser fundada, desejando que a mesma fosse devidamente esclarecida. ${ }^{30}$

Os dois representantes das províncias diretamente atingidas pelo decreto, Amazonas e Grão-Pará, mantiveram, assim, uma mesma posição. Eles defenderam uma interpretação do contrato que tendia a limitar ao máximo o privilégio

\footnotetext{
${ }^{26}$ Anais da Câmara dos Deputados. Sessão de 11 de agosto de 1853, p. 169.

${ }^{27}$ Idem.

${ }^{28}$ Idem, p. 169-170.

${ }^{29}$ Idem, p. 170.

${ }^{30}$ Idem.
} 
de exclusividade cedido à companhia fundada pelo futuro barão de Mauá, ao mesmo tempo em que não o negava, aceitando-o como algo necessário e benéfico. Assim, nem os afluentes do rio Amazonas estariam inclusos no privilégio concedido, nem o comércio poderia, nem que fosse por uma falha interpretativa, estar incluído também. De fato, o que surge aqui é a defesa de interesses bastante nítidos. Segundo estes, a exclusividade deveria ser concedida como uma estratégia para desenvolver e valorizar o rio Amazonas bem como toda a região. Ao mesmo tempo, ela deveria ser oferecida com limitações, para permitir que, uma vez ocorrida esta valorização e este desenvolvimento, outros pudessem lucrar com uma navegação marginal à principal (no caso a dos afluentes do grande rio), bem como com o comércio que seria animado com a chegada dos navios a vapor da nova companhia. Com isso ganhariam todos: o governo central, que considerava vantajoso para o país o privilégio; as elites provinciais - aqui representadas pelos deputados em questão - que lucrariam em um futuro próximo com os frutos do desenvolvimento da sua região; e a "nação”, que veria incorporada à civilização e garantida para o Império um amplo território - até então praticamente inexplorado -, que passaria a ser colonizado pela companhia de navegação.

Apresentando mais uma proposta intermediária, José Inácio Silveira da Motta, deputado pela Província de São Paulo, não concordou com a necessidade do privilégio de exclusividade defendida pelos deputados do Amazonas e do Grão-Pará, entre outros. Segundo sua exposição, a subvenção oferecida pelo governo imperial já garantia à companhia um lucro de 15\% sobre o seu capital inicial - algo inédito no país - tornando, portanto, dispensável o exclusivismo na navegação a vapor por trinta anos. Mesmo assim, como uma espécie de concessão, o deputado paulista afirmou que aceitaria a possibilidade de este privilégio ser concedido, desde que fosse por um período de apenas quinze anos - o mesmo tempo do subsídio - evitando assim a acomodação da companhia e o seu monopólio comercial em toda a região. ${ }^{31}$ Embora mostrasse concordar, dessa forma, com a postura adotada pelos deputados Mendes de Almeida e Ângelo Muniz da Silva Ferraz, o representante de São Paulo discordou frontalmente do primeiro quanto a uma proposta levantada por este e apoiada por João Duarte Lisboa Serra. Para ele a atração de capital estrangeiro para a região amazônica seria um mal e, portanto, deveria ser evitado. Assim, sem se alinhar automaticamente a nenhuma das principais propostas então apresentadas, Silveira da

\footnotetext{
${ }^{31}$ Anais da Câmara dos Deputados. Sessão de 18 de agosto de 1853, p. 247-249.
} 
Motta se posicionou em uma situação de meio termo entre as duas, buscando conciliar, na medida do possível, as ideias divergentes.

Desta forma, durante praticamente todo o mês de agosto de 1853, a Câmara dos Deputados foi agitada pelo embate de diferentes projetos para o desenvolvimento da região amazônica e para sua inserção econômica no conjunto do Império. Chama a atenção o fato de que participaram da discussão deputados de diferentes províncias, todos falando em nome do “interesse nacional”. Dentre estes, os deputados do Amazonas e do Pará adotaram uma posição mais moderada, baseada no conhecimento da região. Apoiaram o contrato celebrado, mas denunciaram seus pontos negativos, como o prazo muito longo do privilégio concedido e o favorecimento da companhia para a navegação dos afluentes. As consequências deste debate indicam que ele não ocorreu em vão, e que o Parlamento de fato possuía papel destacado no processo decisório acerca da navegação a vapor do rio Amazonas.

O que estava em jogo era a melhor maneira de incorporar a região norte e promover nela atividades lucrativas. Este, consensualmente, era o "interesse nacional”, e promover a navegação do Amazonas e a colonização de suas margens era a estratégia defendida por todos. A maneira de fazê-lo, contudo, gerava divergências colocadas em termos quase doutrinários. Todos concordavam com a necessidade de atrair capital privado, mas discordavam sobre o modo mais eficiente de realizá-lo. Os opositores à concessão do monopólio empunhavam a bandeira liberal da livre concorrência como promotora de desenvolvimento; os defensores respondiam com a dura realidade: sem privilégios o capital não viria.

\section{A disputa entre os poderes Executivo e Legislativo na questão da navegação do rio Amazonas}

Não foi somente o embate de diferentes projetos de desenvolvimento para o norte do país que ocupou os membros da Câmara dos Deputados, nas sessões em que foram discutidos os termos do contrato para navegação a vapor do rio Amazonas. Durante os discursos surgiram também, em um dado momento, dúvidas quanto à legitimidade da formulação de tal documento sem prévia consulta ao Parlamento. Por sua vez, os que defendiam a legalidade do ato questionaram a validade das críticas feitas por alguns deputados ao governo. $\mathrm{O}$ desenrolar desta discussão é bastante indicativo do funcionamento do sistema político imperial e do relacionamento existente entre os poderes Executivo e 
Legislativo em meados do século XIX. Por isso, vale a pena deter-se, ainda que brevemente, sobre os termos deste debate.

A matéria entrou em primeira discussão no dia 1 de agosto de 1853. Não obstante esta relativa demora em se discutir um assunto considerado de grande importância estratégica para o país (mais de dois meses entre o envio do decreto para a Câmara, em 13 de maio, e o início das discussões), ${ }^{32}$ a navegação do rio Amazonas não precisou esperar. No primeiro dia do ano de 1853, foi inaugurada a primeira linha de barcos a vapor entre as cidades de Belém, no Pará, e Barra, então capital da Província do Amazonas. Isto antes que o Poder Legislativo tomasse ciência, oficialmente, do contrato firmado entre o governo imperial e Irineu Evangelista de Souza no ano anterior. ${ }^{33}$ Para isso, o governo teria se valido da Lei $n^{0} 586$, promulgada em 6 de setembro de 1850, que o autorizava a estabelecer a navegação a vapor nas águas do Amazonas e do Pará subvencionando, se necessário, as companhias que se dispusessem a realizar esta atividade. ${ }^{34}$

Quando Cândido Mendes de Almeida, deputado pelo Maranhão, subiu à tribuna para se posicionar contra o parecer da comissão de comércio, indústria e artes, iniciando assim as discussões acerca da matéria, a navegação a vapor do rio Amazonas já era uma realidade há mais de seis meses. O que não o impediu de ser pouco receptivo ao parecer. Inicialmente, ele afirmou não ser contra o projeto, mas sim favorável a maiores esclarecimentos quanto ao seu conteúdo. Em seguida, atacou aquilo que pode ser entendido como uma das ideias centrais do contrato firmado com o futuro barão de Mauá. O decreto, afirmava ele, contrariava a Lei $n^{\circ} 586$, pois esta autorizaria o Executivo "a subvencionar companhias com o fim de navegar o Amazonas por meio de barcos a vapor, a promover o seu comércio”, mas não a ceder a exclusividade dessa navegação a apenas uma companhia. ${ }^{35}$ Isso configuraria, portanto, uma invasão de jurisdição por parte do governo imperial, que teria extrapolado a autorização recebida do Legislativo, ao conceder o privilégio de monopólio a Irineu Evangelista de Souza.

A discussão em torno desta lei seria a tônica dos primeiros embates entre os defensores e os opositores do governo no tocante à concessão do privilégio. Viriato Bandeira Duarte afirmou, em seu discurso de 2 de agosto, que a Lei $n^{\circ} 586$ dava, sim, ao governo a habilitação "para consignar prestações a quem

\footnotetext{
${ }^{32}$ Anais da Câmara dos Deputados. Sessão de 13 de maio de 1853, p. 189.

${ }^{33}$ Relatório do Ministério do Império, 14 de maio de 1853, p. 37-38.

${ }^{34}$ Idem, 15 de maio de 1851, p. 37.

${ }^{35}$ Anais da Câmara dos Deputados. Sessão de 1 de agosto de 1853, p. 7.
} 
se propusesse a manter a dita navegação [do rio Amazonas]” ${ }^{36}$ E, além disso, o privilégio da navegação exclusiva por trinta anos tinha sido concedido por meio de um decreto imperial, não cabendo, portanto, à Câmara discutir tal assunto. Este argumento coloca uma questão central para o entendimento da relação existente entre os poderes Executivo e Legislativo do Império. De um lado, havia o entendimento de que a última palavra sobre a concessão cabia ao Legislativo, que delegava ao Executivo a tarefa, mas com a ressalva de que este só poderia atuar nos estritos limites daquela delegação, como defendera Mendes de Almeida. De outro lado, a posição de Bandeira Duarte, segundo a qual o Legislativo, naquela matéria, não tinha autonomia, ou mesmo poder suficiente, para contestar uma ação do Executivo. Caberia aos deputados, portanto, apenas tomar ciência das decisões do governo e agir da melhor forma possível no sentido de viabilizá-las, nas partes em que dependiam de aprovação da assembleia. ${ }^{37}$

De fato, com o aparente propósito de justificar uma ausência no voto da comissão da qual fazia parte, o deputado Viriato Bandeira Duarte havia tocado em um ponto vital da convivência entre os poderes Executivo e Legislativo o que, como não poderia deixar de ser, teve sérias consequências na continuação dos debates. Mesmo com esta questão ainda pendente, o contrato acabou sendo aprovado, em primeira discussão, ainda no dia 2 de agosto, iniciando-se a segunda discussão nove dias depois. ${ }^{38}$

A estratégia adotada, então, por aqueles que eram contra o decreto foi a de tentar forçar a ida ao plenário do ministro do Império, Francisco Gonçalves Martins, para responder aos questionamentos acerca do documento e aos ataques dirigidos ao governo. Foi neste sentido que o deputado pela Província da Bahia, Ângelo Muniz da Silva Ferraz, apresentou, logo no início dos discursos do dia 11, um requerimento para adiamento da discussão acerca do projeto 71, sob a alegação de o mesmo conter algumas ideias que necessitavam de maior esclarecimento, como, por exemplo, o alcance geográfico do privilégio de exclusividade. ${ }^{39}$

Foi esta a senha para que uma nova discussão ocorresse nesse dia: adiarse ou não a discussão até que o ministro do Império comparecesse à Câmara para prestar esclarecimentos? Viriato Bandeira Duarte estava convencido de que a presença do ministro não era necessária, assim como tampouco era

\footnotetext{
${ }^{36}$ Idem. Sessão de 2 de agosto de 1853, p. 27.

${ }^{37}$ Idem.

${ }^{38}$ Idem, p. 30-31.

${ }^{39}$ Idem. Sessão de 11 de agosto de 1853, p. 168.
} 
necessário o adiamento do debate. Em sua opinião, não havia razão para dúvidas quanto ao alcance do privilégio concedido à companhia de navegação. A comissão de comércio, indústria e artes teria se valido das palavras da lei e do contrato celebrado entre o governo e Irineu Evangelista de Souza para emitir seu voto e elaborar o projeto que ora se discutia. Bastava, portanto, ler os seus dispositivos para entendê-lo em sua plenitude. ${ }^{40}$ Por sua vez, como visto anteriormente, o deputado pela recém criada Província do Amazonas, João Wilkens de Mattos, não se mostrou tão convencido acerca da clareza do projeto. Embora tenha afirmado ser defensor da criação da companhia e do exercício de suas atividades na região amazônica, defendeu o adiamento da discussão até que o contrato pudesse ser esclarecido completamente. Posição idêntica foi adotada pelo representante do Grão-Pará, Fausto Augusto de Aguiar.

Após estes discursos, o requerimento de adiamento acabou sendo aprovado. ${ }^{41}$ Os deputados exerceram, dessa forma, uma prerrogativa do Poder Legislativo, ao convocar o Executivo para esclarecer perante a casa as medidas por ele tomadas. Ao ministro não havia alternativa; teria de comparecer e prestar os esclarecimentos pedidos. Na lógica do regime representativo do século XIX, tratava-se de uma das formas de fiscalização do Legislativo sobre o Executivo, para que se evitassem abusos. ${ }^{42}$

Na sessão de 18 de agosto de 1853, além dos discursos que evidenciaram as diferentes posições dos deputados sobre a região norte do país, o tema da relação entre os poderes Executivo e Legislativo também esteve na ordem do dia. O deputado pela Bahia, Ângelo Muniz da Silva Ferraz, retomou a discussão acerca das competências de ambas as esferas de poder, indagando ao ministro do Império se a concessão do privilégio de exclusividade não estaria dependente de aprovação do Parlamento. ${ }^{43}$ Aproveitou a oportunidade, portanto, para acusar a invasão de jurisdição praticada pelo governo imperial, ao adotar uma medida que seria de competência exclusiva do Poder Legislativo:

\footnotetext{
${ }^{40}$ Idem, p. 169.

${ }^{41}$ Anais da Câmara dos Deputados. Sessão de 12 de agosto de 1853, p. 174.

${ }^{42}$ Sobre o sistema representativo, ver SARTORI, Giovanni, A teoria da representação no Estado representativo moderno. Belo Horizonte: Revista Brasileira de Estudos Políticos, 1962; PITKIN, Hannah Fenichel, The concept of representation. Berkeley/Los Angeles: University of California Press, 1972; FERREIRA, Silvestre Pinheiro. Manual do cidadão em um governo representativo de princípios de direito constitucional, administrativo e das gentes (seleção). In: FERREIRA, Silvestre Pinheiro Ferreira. Ideias políticas. Rio de Janeiro: Documentário, 1976, p. 107-176.

${ }^{43}$ Anais da Câmara dos Deputados. Sessão de 18 de agosto de 1853, p. 235-236.
} 
São estas as considerações que eu tenho a fazer: temo muito dos privilégios exclusivos, e pedirei ao Sr. Ministro também que me informe se entende que a concessão desse privilégio exclusivo não depende da aprovação do corpo Legislativo; porquanto, no ofício de remessa desse contrato unicamente S. Ex. se refere neste ponto a um dos dois artigos do mesmo contrato, e não a respeito do privilégio exclusivo. Eu tenho uma opinião muito segura a este respeito, e é que o governo não pode conceder privilégios exclusivos sem autorização ou dependência de aprovação do corpo Legislativo. Neste ponto o corpo Legislativo não concedeu autorização, concedeu auxílio pecuniário, parece que a lei quis excluir a ideia do privilégio; e se depende de aprovação nossa esse privilégio, eu pediria ao Sr. Ministro que considerasse bem se haverá boas razões para ele se conservar. ${ }^{44}$

Imediatamente após este discurso, o ministro do Império subiu à tribuna para responder às indagações. Iniciou sua fala defendendo o governo, em primeiro lugar, da acusação de ter concedido o exclusivismo da navegação sem consulta ao Poder Legislativo, justificando tal ato pelo caráter urgente da questão da navegação amazônica. Além disso, Gonçalves Martins afirmou que, em diversas ocasiões no passado, medidas que dependiam da aprovação da Câmara foram adotadas à sua revelia, sem que por isso os deputados se levantassem em protesto. ${ }^{45}$ Dessa forma, o ministro não apenas assumiu a invasão da jurisdição parlamentar por parte do governo imperial, como denunciou o uso recorrente desta medida em outras oportunidades.

Para o deputado Mendes de Almeida, entretanto, a situação não era tão facilmente justificável. Segundo ele, o governo não poderia ter concedido, em hipótese alguma, o privilégio de exclusividade na navegação a vapor do rio Amazonas sem ter consultado antes o Poder Legislativo, uma vez que não havia no país lei alguma que o autorizasse a isto. ${ }^{46}$ João Duarte Lisboa Serra, igualmente deputado pelo Maranhão, também criticou a concessão do privilégio pelo governo sem consulta ao Parlamento, classificando tal ato de abuso e ilegalidade que o uso anterior não poderia justificar. Percebe-se, neste discurso, um tom de desabafo, no qual o representante maranhense cobrou, ainda, a completa e breve resolução de todas as pendências entre o governo imperial e a Assembleia Geral, sem que isso resultasse em prejuízo para a navegação do rio Amazonas.

\footnotetext{
${ }^{44}$ Idem, p. 235.

45 Idem, p. 236.

${ }^{46}$ Idem, p. 238.
} 
Me inclino muito à opinião daqueles que duvidam do bom direito do governo para sem preceder autorização especial do corpo Legislativo conceder privilégios; mas julgo também que não é no caso vertente que devemos resolver essa grande questão. Eu desejara, senhores, que não só essa como outras muitas questões importantes que continuam em pé fossem de uma vez decididas de modo que os nossos princípios constitucionais ficassem bem definidos. (...) Não me pode satisfazer completamente a explicação dada pelo nobre ministro, quando, para defender-se, disse que fez o que sempre se tem em casos idênticos praticado, porque não considero semelhante prática, sendo abusiva como me inclino a crer, suficiente para justificar novos atos da mesma natureza. Se tal princípio pudesse prevalecer, se cada governo devesse em tudo imitar o seu antecessor, a responsabilidade dos ministros seria uma quimera e os abusos se perpetuariam; poderíamos mesmo chegar ao absurdo de censurar um ministro que, desobedecendo à lei da imitação, quisesse dar fiel execução às leis do país; poderíamos chegar ao absurdo ainda mais monstruoso de alegar em sua defesa o ministro que fosse acusado por abuso de poder, que "a prática anterior era toda igualmente abusiva, e não devia o governo, por um ato regular e conforme às leis, ir perturbar a harmonia, a homogeneidade desse belo quadro de irregularidades". ${ }^{47}$

O tom de todos os discursos proferidos na sessão de 18 de agosto na presença do ministro do Império, Francisco Gonçalves Martins, era o mesmo. A maioria dos deputados que se pronunciaram sobre o tema repudiava o fato de o governo ter extrapolado as instruções constantes na Lei n ${ }^{\circ} 586$ de setembro de 1850, assumindo responsabilidades exclusivas do Poder Legislativo. E fazia a mais absoluta questão de demonstrar seu descontentamento, através de suas falas inflamadas.

O dia 19 de agosto de 1853 marcou a última oportunidade de discussões sobre o projeto apresentado pela comissão de comércio, indústria e artes. Antes mesmo do início dos debates, foram apresentadas duas emendas à mesa, de autoria dos deputados Ângelo Muniz da Silva Ferraz e Joaquim José Pacheco. Ambas foram formuladas para alterar o documento no que tocava à concessão do privilégio de exclusividade. Pela emenda do deputado Pacheco, que acabaria sendo rejeitada, o contrato celebrado entre o governo imperial e Irineu Evangelista de Souza ficava aprovado, com exceção do privilégio. Entretanto, o governo seria autorizado a elevar a subvenção concedida à companhia de navegação. ${ }^{48}$ Já pela emenda do deputado Ângelo Muniz da Silva Ferraz, que foi aprovada no final do dia, o con-

\footnotetext{
${ }^{47}$ Idem, p. 242.

${ }^{48}$ Anais da Câmara dos Deputados. Sessão de 19 de agosto de 1853, p. 253.
} 
trato também era aceito, mas o privilégio de exclusividade deveria ser resgatado pelo governo mediante indenização, do modo que julgasse mais conveniente. ${ }^{49}$

No mesmo sentido de crítica ao Poder Executivo, e com as mesmas argumentações, caminharam os curtos discursos de Fausto Augusto de Aguiar, deputado pelo Pará, e de Martim Francisco Ribeiro de Andrada, então representante da Província de São Paulo. A fala deste último, entretanto, chama a atenção pelo tom utilizado na censura ao governo, deixando transparecer a imagem de que a relação entre ambas as esferas de poder - ou, ao menos, entre o governo imperial e seus opositores na Câmara dos Deputados - estava realmente bastante desgastada. Disse Ribeiro de Andrada:

o censuro porque ele concedeu um privilégio que não estava na letra da lei; censuro-o quando alienou bens nacionais, e concedeu terras devolutas pertencentes à nação sem autorização do corpo Legislativo; e censuro-o ainda quando no decreto que precede o contrato se declara que ele voltará ao corpo Legislativo unicamente para que este o aprove somente na parte relativa à dispensa de imposições. O que é de uma estranhável prepotência e revela o desprezo da lei.

(...)

Do simples fato, senhores, de estabelecer o governo o privilégio em favor da companhia, não se deve deduzir que já existem direitos adquiridos, porque nenhum privilégio pode ser concedido pelo governo, pois isso é da atribuição do corpo Legislativo.

(..)

Suponho que, quando se trata de uma disposição legislativa como essa, que implica a concessão de direitos não consignados na legislação vigente, só quem é competente para alterar o que há a tal respeito é o Poder Legislativo, e nunca o Executivo, o qual quando muito poderá ter a iniciativa da proposta, que nunca deverá ser considerada com força de lei. ${ }^{50}$

O parecer apresentado pela comissão de comércio, indústria e artes foi aprovado, porém com a emenda apresentada no início do dia por Ângelo Muniz da Silva Ferraz, que tornava obrigatório o resgate do privilégio de exclusividade, mediante o pagamento de indenização à companhia de navegação. ${ }^{51}$

Enviado ao Senado, o contrato provocou, novamente, ácidas críticas ao governo. Alguns dos termos em que estes ataques foram concebidos foram,

\footnotetext{
49 Idem.

${ }^{50}$ Anais da Câmara dos Deputados. Sessão de 19 de agosto de 1853, p. 260.

${ }^{51}$ Idem, p. 260.
} 
até mesmo, mais duros do que os utilizados na Câmara dos Deputados, como demonstra a seguinte fala do senador dom Manuel de Assis Mascarenhas:

O Sr. Ministro do Império é o maior violador de leis que tem havido, porque conhece a terra em que está, e sabe que assim caminha para o capitólio; mas muito perto deste fica a rocha Tarpéa... É impossível que a Providência não mande um castigo horroroso sobre o Brasil por causa do procedimento deste governo... demônio... mas o Sr. Presidente não gosta que se use deste termo. ${ }^{52}$

O senador foi ainda mais longe. Propôs que o Parlamento se unisse com o objetivo de derrubar o ministério do qual Francisco Gonçalves Martins - que estava presente na sessão - fazia parte, utilizando-se das prerrogativas garantidas pelo regime representativo:

Mas porque o Corpo Legislativo não toma o seu lugar, não censura esses ministros, não lhes tira o apoio, e os faz cair por força? Eles poderiam recorrer a uma dissolução; porém o povo havia de mandar para a câmara temporária aqueles que houvessem censurado os ministros. ${ }^{53}$

Não havia outra alternativa ao governo imperial que não fosse acatar a decisão do Parlamento. Na intensa negociação entre os poderes Executivo e Legislativo, o primeiro foi obrigado a recuar. Assim, no relatório do ministro do Império, Luiz Pedreira do Couto Ferraz, de 14 de maio de 1854, era informado solenemente que estavam adiantadas as negociações para o resgate do privilégio:

No intuito de corresponder às intenções com que foi promulgado o Decreto n ${ }^{\circ} 726$ de 3 de outubro do ano passado [1853], trata o governo de resgatar o privilégio concedido por 30 anos de navegação exclusiva à Companhia de que é presidente o comendador Irineu Evangelista de Sousa.

Para este fim recebeu uma proposta para a novação do contrato celebrado entre o empresário e o governo imperial, a qual já foi examinada pelo procurador da Coroa, Soberania e Fazenda Nacional, e pela Seção dos Negócios do Império do Conselho d’Estado. Pende

\footnotetext{
${ }^{52}$ Anais do Senado. Sessão de 24 de agosto de 1853, p. 89. Todos os discursos presentes nos Anais do Senado e citados neste texto estão disponíveis, em versão eletrônica, no site www.senado.gov.br. ${ }^{53}$ Idem, p. 89-90.
} 
hoje de discussão entre o governo e o dito empresário acerca de certas condições, e o que se resolver definitivamente sobre este objeto ser-vos-á comunicado.

Pretende o governo no novo contrato regular melhor a mesma navegação, e estabelecer a de alguns de seus afluentes, como sejam especialmente o rio Negro e o Madeira, que em grande extensão se prestam à navegação por vapor.

Pretende igualmente dar o devido impulso à fundação de colônias nas margens dos ditos rios, e de outros importantes, a que se comprometeu a Companhia. ${ }^{54}$

Como resultado de tais negociações, foi apresentado à Câmara, no relatório do Ministério do Império de 14 de maio de 1855, o novo contrato firmado entre o governo imperial e a Companhia de Navegação e Comércio do Amazonas, em 2 de outubro de 1854. Este novo documento substituía o contrato original, de 30 de agosto de $1852 .{ }^{55}$ Por este novo acordo, anexo ao Decreto ${ }^{\circ} 1.445$, a companhia abriu mão, além do privilégio, da preferência para navegação dos afluentes do rio Amazonas, e sobre a abertura de vias de comunicação lateral outro ponto bastante criticado nas discussões da Câmara dos Deputados. Mais ainda, ficou comprometida a operar duas novas linhas além das originais - uma no rio Tocantins, entre Belém e a Vila de Baião, com escala em Cametá; e outra no rio Negro entre a cidade de Barra e a povoação de Santa Isabel. Além disso, ficou obrigada a fundar 12 novas colônias, não previstas inicialmente. ${ }^{56}$

Em compensação à perda do privilégio de exclusividade e à aquisição de novos encargos não previstos no contrato original, o governo cedeu à companhia 70 territórios de 2 léguas quadradas cada um, além de terrenos de marinha devolutos. ${ }^{57} \mathrm{O}$ novo contrato passou a vigorar em janeiro de 1855:

Em janeiro do corrente ano [1855] começou a execução do novo contrato, fazendo o serviço da 1a, 3a e 4a linhas os vapores Marajó, Rio Negro, Cametá e Monarca, e em março chegou da Inglaterra outro de muito maior lotação, denominado Tapajós, que seguiu logo de Belém, transportando 129 colonos contratados em Portugal pela Companhia para a nova colônia - Mauá - fundada nas imediações da cidade da Barra. ${ }^{58}$

Com isso, o desentendimento entre os poderes imperiais ficaria, ao menos temporariamente, resolvido, uma vez que, segundo afirmação do ministro do

\footnotetext{
${ }^{54}$ Relatório do Ministério do Império, 14 de maio de 1854, p. 23.

${ }^{55}$ Idem, 14 de maio de 1855, p. 35-37.

${ }^{56}$ Idem, p. 36.

${ }^{57}$ Idem.

${ }^{58}$ Idem.
} 
Império, "as intenções do Poder Legislativo ficarão satisfeitas do melhor modo que era possível". 59

Apenas dois anos depois, em 1857, nova reforma teve de ser realizada. O motivo foram os insistentes pedidos de Irineu Evangelista de Souza, que afirmava estar sobrecarregado com os encargos contraídos. Desta vez, antes de assinar acordo com o empresário, o governo imperial realizou consulta ao Parlamento, que consentiu - mas apenas após acalorados debates. Segundo o novo acordo, a Companhia de Navegação e Comércio do Amazonas ficava desobrigada da fundação de colônias nas margens do grande rio, suprimia uma das linhas operadas na região - a que ligava a cidade de Manaus a Santa Izabel do Rio Negro, de baixa lucratividade -, e deixava de realizar uma das viagens mensais da linha principal, entre Belém e Manaus. Além disso, a subvenção mensal da companhia foi aumentada de trinta e um para trinta e cinco contos de réis mensais, somando um total de quatrocentos e vinte contos de réis anuais. ${ }^{60}$ Aumentavam-se, portanto, os subsídios financeiros à companhia do futuro barão de Mauá, e diminuíam-se suas obrigações. Exatamente como pedira o empresário, e como concordaram os poderes Executivo - que submetera o projeto ao Parlamento e colaborara para sua aprovação - e Legislativo. Assim como em 1853, a Assembleia Geral assumiu papel fundamental no processo decisório acerca da navegação a vapor do rio Amazonas. Exatamente como previa o sistema político de tipo representativo, que vigorava no Império em meados do século XIX

Recebido: outubro/2009 - Aprovado: outubro/2009.

\footnotetext{
${ }^{59}$ Idem, p. 35.

${ }^{60}$ Relatório do Ministério do Império, 6 de maio de 1858, p. 56-58.
} 